\title{
USO DO INSTRUMENTO TDR PARA DETERMINAÇÃO DO TEOR DE ÁGUA EM DIFERENTES CAMADAS DE UM LATOSSOLO ROXO DISTRÓFICO
}

\author{
Elio Lemos da Silva $^{1}$ \& Eliezer Santurbano Gervásio ${ }^{2}$
}

\begin{abstract}
RESUMO
O presente estudo teve como objetivo verificar a validade dos dados de umidade volumétrica fornecidos pelo instrumento TDR - "Time Domain Reflectometer - Trase System", para as camadas 0 - 20, 0 - 40 e 0 - $60 \mathrm{~cm}$ de um Latossolo Roxo Distrófico de textura argilosa, sob experimento de cafeicultura irrigada na Universidade Federal de Lavras. As relações entre a umidade real (determinada pelo método padrão de estufa) e a constante dielétrica Ka (característica do solo obtida pelo TDR) e entre a umidade real e a umidade dada pelo instrumento, permitiram ajustar-se, para cada camada, uma equação do terceiro grau, para umidade versus Ka e uma equação linear para a umidade real versus a umidade dada pelo instrumento. Constatou-se, através do teste $\mathrm{F}$, que não houve diferença significativa a nível de $1 \%$ de probabilidade entre as equações geradas para cada camada de solo, o que sugere a utilização de uma equação única para o solo estudado até a profundidade de $60 \mathrm{~cm}$. Comparou-se também, a equação geral obtida para a umidade real como função de Ka com a equação do aparelho (Equação de Topp et al.,1980) observando-se diferença significativa entre elas. O instrumento subestima a umidade volumétrica para o Latossolo na área em estudo.
\end{abstract}

Palavras-chave: reflectometria, constante dielétrica, umidade

\section{THE USE OF TDR FOR MOISTURE DETERMINATION IN DIFFERENT LAYERS OF A DYSTROPHIC DUSKY RED LATOSSOL}

\begin{abstract}
The present study aimed at validating soil to evaluate moisture content data given by the instrument TDR - Time Domain Reflectometer, for the layers 0 - 20, 0 - 40 and 0 - 60 centimeters of a Dystrophic Dusky Red Latossol under an irrigated coffee experiment at the Federal University of Lavras. A third degree equation for the relationship between the soil moisture content determined by oven method and soil dielectric constant Ka given by the instrument, and a linear equation for the relationship between the real soil moisture content and TDR given soil moisture content for each under in study was established. There was no significant difference, at probability of $1 \%$, among the fitted equations for the different layers, which suggests that a general equation representing the total depth of 0 - 60 centimeters, to estimate soil moisture content using TDR, may be used. The general equation of the real soil moisture content as function of soil dielectric constant was compared with that of the instrument inserted equation (Topp equation) and it was concluded the latter significantly underestimated the soil moisture content values for the Latossol in the studied area.
\end{abstract}

Key words: reflectometry, dielectric constant, soil moisture content

\footnotetext{
${ }^{1}$ Eng. Agrônomo, Ph.D., Professor do Departamento de Engenharia da Universidade Federal de Lavras, CP 37, CEP 37200 - 000 , Lavras, MG, Fone: (035) 829 1158, Fax: (035) 829 14.82. E-mail: elemos@ufla.br

${ }^{2}$ Eng. Agrônomo, M.Sc., Pesquisador do Departamento de Engenharia da Universidade Federal da Lavras, Fone: (035) 8220970 E-mail: gervasio@ufla.br
} 


\section{INTRODUÇÃO}

A determinação da umidade do solo constitui uma medida imprescindível nas atividades agrícolas, envolvendo as relações água-solo-planta-atmosfera. São vários os métodos usados para se estimar a umidade do solo, como os blocos de resistência elétrica descritos por Armstrong et al. (1985), os psicrômetros de solo (Richards \& Caldwell, 1987), tensiômetros (Rice, 1969) e a moderação de neutrons. Um método ideal seria aquele que usasse uma propriedade física do solo ou uma característica altamente correlacionada ao seu teor de água. Tal propriedade deve ser confiável e capaz de ser avaliada diretamente no campo, sem alteração das características físicas do solo; este método pode ser a medição da constante dielétrica do solo, uma propriedade que representa a relação entre a capacitância de um meio isolador e o espaço livre. O instrumento TDR (Time Domain Reflectometer) faz uso dessa propriedade da água para determinar a sua quantidade no solo; o TDR estabelece a constante dielétrica do solo, através da medição do tempo (t) para um pulso eletromagnético emitido em barras condutoras paralelas de comprimento L, cravadas no solo, alcançar o seu final e voltar ao ponto de emissão. Topp et al. (1980) propuseram um polinômio do terceiro grau para conversão dos valores da constante dielétrica do solo em umidade com base em volume. A precisão, segundo os autores, é suficiente para sugerir o uso do TDR sem necessidade de calibração para os diferentes solos. Topp \& Davis (1985) enfatizam que o tipo de solo e/ou sais solúveis não afetam os valores da umidade determinados com TDR. Silva (1995) suspeitando das informações de um fabricante do instrumento de que não haveria necessidade de calibração, decidiu avaliar os resultados de umidade do solo fornecidos pelo TDR encontrando, para um solo barro arenoso no sudoeste do Arizona, EUA, uma relação linear entre a umidade do solo expressa em base de volume e a umidade dada pelo TDR. Silva (1998) constatou, ainda, que a equação de Topp não pode ser usada para a camada superficial $(0-15 \mathrm{~cm})$ de um Latossolo Roxo-Distrófico. O instrumento TDR já tem embutida, em seu sistema, a equação gerada por Topp et al. (1980) para solos americanos mas, com base em determinações e observações de campo, suspeitou-se do uso de tal equação para os solos brasileiros, decidindo-se por elaborar uma equação específica para cada um dos diferentes tipos de solo encontrados no país. O presente trabalho visa, portanto, facilitar a determinação da umidade, inicialmente em Latossolo Roxo-Distrófico, com uso do TDR, através da relação típica da umidade do solo com a constante dielétrica determinada pelo instrumento.

\section{MATERIAL E MÉTODOS}

A determinação da relação entre a constante dielétrica e a umidade volumétrica do solo foi conduzida no Laboratório de Hidráulica da Universidade Federal de Lavras, no período de março a outubro de 1998. Para a calibração do TDR (Soil Moisture, modelo Trase System I 6050X1) utilizaram-se colunas de PVC de $100 \mathrm{~mm}$ de diâmetro, nos comprimentos de 25,45 e $65 \mathrm{~cm}$, as quais receberam as hastes de 22,42 e 62 $\mathrm{cm}$, respectivamente. O solo utilizado foi classificado como Latossolo-Roxo de textura argilosa e as colunas foram preparadas a partir de terra fina seca em estufa de material coletado das camadas em estudo, de maneira a se ter densidade global próxima do valor de campo. Após o enchimento das colunas, instalaram-se as hastes correspondentes às alturas das colunas, determinando-se o valor da constante dielétrica nesta condição; posteriormente, submeteu-se o conjunto à saturação e iniciou-se a calibração através da leitura do TDR e pesagem do conjunto, para determinação do conteúdo de água. Feitas as leituras e as pesagens, as colunas eram deixadas para secar à sombra e, em seguida, envolvidas com plástico para uniformização da umidade. Ficavam envolvidas no plástico por um dia antes de se proceder a novas leituras e pesagens. O tempo entre uma avaliação e outra aumentava, a medida em que o solo ficava mais seco. Para cada coluna efetuaram-se três ciclos de coleta de dados, cada um correspondendo ao intervalo entre a saturação e o momento em que a variação de umidade da coluna era praticamente nula. De posse dos dados, transformaram-se os valores de umidade gravimétrica para volumétrica, através da densidade do solo e plotou-se as curvas de umidade volumétrica do solo, em função da constante dielétrica (Ka) e da umidade volumétrica determinada pelo TDR. Obtevese uma equação para cada comprimento de haste e uma equação geral correspondente a todos os pares de pontos coletados nas três colunas avaliadas. As três equações determinadas em função do comprimento da coluna e a equação geral, foram comparadas pelo teste $\mathrm{F}$ para variância.

\section{RESULTADOS E DISCUSSÃO}

A Figura 1 apresenta os diagramas de dispersão e as curvas com as correspondentes equações de regressão da umidade do solo (teta) em função do Ka e da umidade lida pelo TDR. Através da análise de variância verificouse que não houve diferença significativa entre as equações geradas para cada profundidade, tanto para a umidade do solo em função da constante dielétrica como para a umidade do solo em função da umidade lida pelo TDR, possibilitando o uso da equação geral, independentemente do comprimento da haste (Tabela 1). Observou-se, também, pela análise de variância, que as equações "geral" de campo e de Topp et al. (1980) foram diferentes estatisticamente, a nível de $1 \%$ de probabilidade, conforme mostra a Tabela 2. A equação de Topp subestima a umidade para o Latossolo em estudo. Tais constatações possibilitam a utilização da equação geral $\theta=0,0315+1,0727 \cdot T D R\left(\mathrm{r}^{2}=0,9743\right)$ ou $\theta=-4,95 \cdot 10^{-2}+3,76 \cdot 10^{-2} \cdot K_{a}-1,04 \cdot 10^{-3} \cdot K_{a}{ }^{2}+1,38 \cdot 10^{-5} \cdot K_{a}{ }^{3}$ $\left(\mathrm{r}^{2}=0,9774\right)$ para as profundidades $0-20,0-40 \mathrm{ou} 0-60 \mathrm{~cm}$ do Latossolo em estudo, usando-se, respectivamente, a leitura de umidade $\mathrm{em}^{3} \mathrm{~cm}^{3} \mathrm{~cm}^{-3}$ no TDR ou a constante dielétrica Ka. 


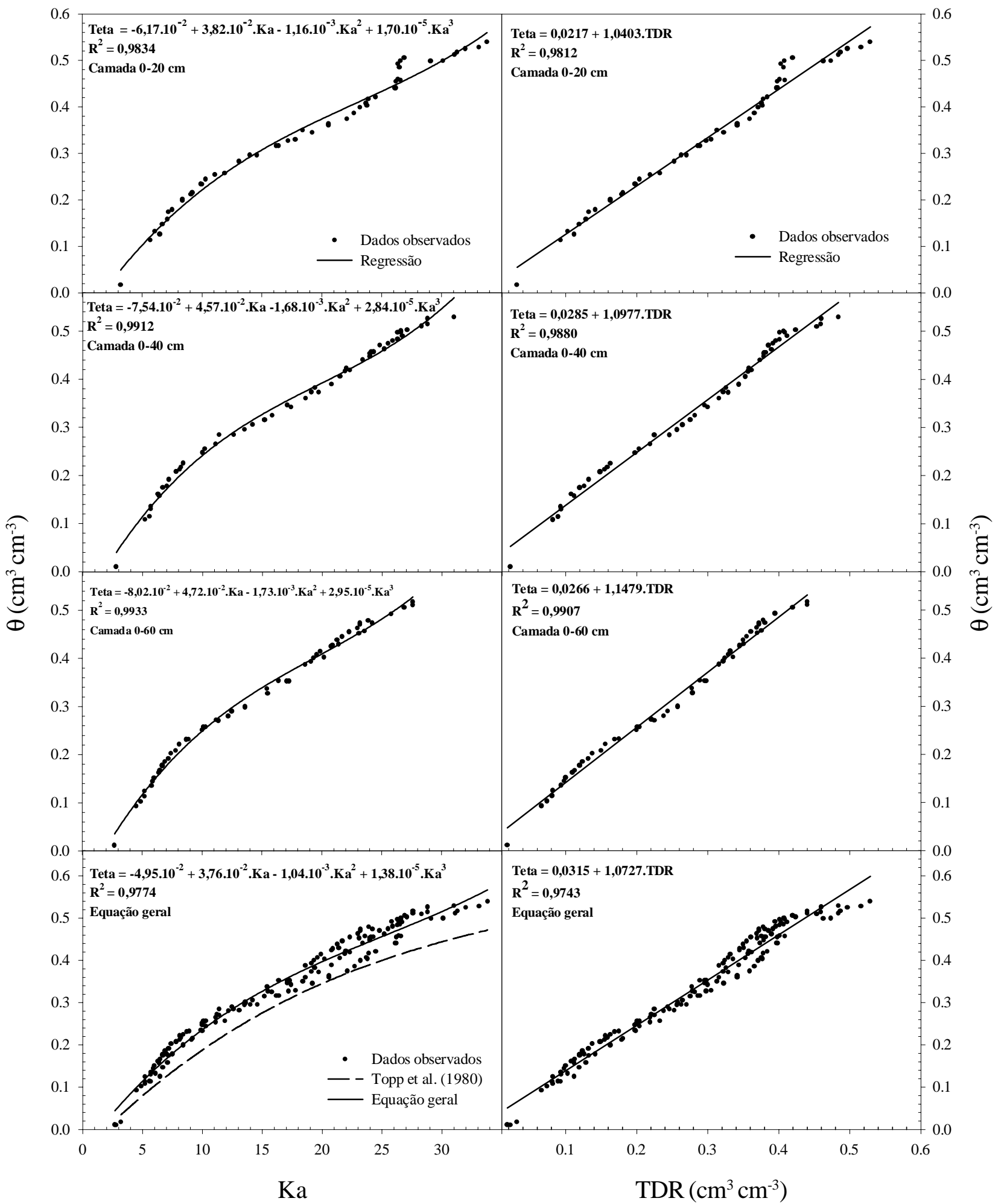

Figura 1. Equações da umidade do solo em função da constante dielétrica (Ka) e umidade determinada pelo TDR

Tabela 1. Análise de variância para as equações de umidade do solo em função da constante dielétrica e umidade lida pelo TDR

\begin{tabular}{lrll}
\hline \multirow{2}{*}{ Causa de Variação } & \multirow{2}{*}{ G.L. } & \multicolumn{2}{c}{ Q.M. } \\
& & $\theta=\mathrm{f}(\mathrm{Ka})$ & $\theta=\mathrm{f}(\mathrm{TDR})$ \\
\hline Equações & 3 & $0,0353 \mathrm{NS}$ & $0,0340 \mathrm{NS}$ \\
Resíduo & 648 & 0,0186 & 0,0181 \\
\hline Total & 651 & & \\
\hline ns Não signnificativo & &
\end{tabular}

Tabela 2. Análise de variância para as equações "geral" de campo e de Topp et al. (1980), de umidade do solo em função da constante dielétrica

\begin{tabular}{lcc}
\hline \multicolumn{1}{c}{ Causa de Variação } & G.L. & Q.M. \\
\hline Equações & 1 & $0,2099^{* *}$ \\
Resíduo & 324 & 0,0164 \\
\hline Total & 325 & \\
\hline${ }^{* *}$ Significativo a nível de $1 \%$ de probabilidade & &
\end{tabular}




\section{CONCLUSÕES}

Conclui-se que, para o Latossolo Roxo Distrófico, a equação embutida no instrumento TDR (Equação de Topp) subestima os valores reais de umidade volumétrica. Pode-se usar o instrumento TDR para, através dos dados fornecidos de umidade ou da constante dielétrica, estimar-se a umidade volumétrica real, usando-se uma equação única válida para as camadas 0-20, 0-40 e $0-60 \mathrm{~cm}$ de profundidade.

\section{REFERÊNCIAS BIBLIOGRÁFICAS}

ARMSTRONG, C.F.; LIGON, J.T.; McLEOD, M.F. Automated system for detailed measurement of soil water potential profiles using watermark brand sensors. In: Technical Publication. n.2707, S. C. Agriculture Experimental Station, 1985. p.201-206.

RICE, R. A fast-response, field tensiometer system. Transaction of ASAE, St. Joseph, v.12, p.48-50, 1969.
RICHARDS, J.H.; CALDWELL, M.M. Hydraulic lift: Substantial nocturnal water transport between soil layers by Artemisia tridentata roots. Oecologia, v.73, p.486-489, 1987.

SILVA, E.L. da. Irrigation methods and management effects on leaf lettuce (Lactaca sativa, L.) water use and nitrogen leaching. Tucson: The University of Arizona, 1995. 143p. Ph.D. Thesis

SILVA, E.L.da. Determinação automática do teor de água em Latossolo Roxo Distrófico com uso de reflectometria de onda. In: CONGRESSO BRASILEIRO DE ENGENHARIA AGRÍCOLA, 27. Poços de Caldas, MG, 1998. Anais... Poços de Caldas: UFLA, SBEA, 1998.

TOPP, G.C.; DAVIS, J.L. Time- domain reflectometry. Advances in Irrigation, v. 3, p.107-127, 1985.

TOPP, G.C.; DAVIS, J.L.; ANNAN, A.P. Electromagnetic determination of soil water content: Measurement in coaxial transmission lines. Water Resources Research, v.16, p.574-582, 1980. 